\title{
Ethical Leadership in Intercollegiate Sport: Challenges, Opportunities, Future Directions
}

\author{
Laura Burton \\ University of Connecticut \\ Jon Welty Peachey \\ University of Illinois
}

\begin{abstract}
Given the significant issues leaders face in the intercollegiate sport context, the need to lead ethically is paramount. This special issue, Ethical Leadership in Intercollegiate Sport, highlights the need for ethical leadership, explores enhancing ethical leadership and ethical decision-making, and examines ways to reduce unethical behavior within intercollegiate athletics. This introductory paper defines ethical leadership and identifies opportunities to better understand ethical leadership in the context of intercollegiate sport.
\end{abstract}

Keywords: ethics, leadership, intercollegiate sport

We write this introduction to the Special Issue on Ethical Leadership in Intercollegiate Sport at a time of significant upheaval in intercollegiate athletics. The 2014 women's and men's National Collegiate Athletic Association (NCAA) basketball tournaments have concluded, and the contracts to broadcast those games are lucrative, to say the least (ESPN, 2011; O'Toole, 2010). In the coming years, with the assistance of those television contracts and additional major corporate sponsorships, the NCAA is projected to surpass annual revenue of $\$ 1$ billion (Jacobson, 2014). Interspersed throughout the coverage of these major revenue-producing tournaments are advertisements (or public information announcements) about the NCAA and its role in supporting the lives of all student-athletes. ${ }^{1}$ Despite the claims put forward by the NCAA, there is reasonable skepticism from the general public regarding who truly benefits from college athletics, particularly when focusing on athletes in the revenueproducing sports of men's basketball and football (Branch, 2011, Grasgreen, 2014).

An antitrust lawsuit has been filed on behalf of college athletes alleging the NCAA operates as a cartel restricting the ability of college athletes in the revenue producing sports to earn income above the cost of their college scholarships (Lederman,

Burton is with Educational Leadership, University of Connecticut, Storrs, CT. Welty Peachey is with the Dept. of Recreation, Sport and Tourism, University of Illinois, Champaign, IL. Address author correspondence to Laura Burton at laura.burton@uconn.edu. 
2014). In addition, former college athletes are filing a class action lawsuit challenging the NCAA's claims that a full scholarship for athletic participation covers the actual cost of college attendance (Fenno, 2014). Further, scholars who have examined graduation rates in revenue-generating sports have noted that college athletes, most notably Black athletes competing at PWIs (predominantly white institutions), are graduating at a significantly lower rate than comparable full-time college students (Southall, Eckard, Nagel, Keith, \& Blake, 2013; see also Cunningham, 2012). Finally, academic scandals, one of the most recent being the University of North Carolina scandal of 'paper courses' for athletes and admitting athletes unable to read at the college level, challenge the benefits of the scholarships provided to athletes in revenue-producing sports (Barrett, 2014). These lawsuits, academic indignities, and the unionization challenge brought forth at Northwestern University (see Staurowsky, 2014) shed light on the unfair practices that revenue-producing athletes are subject to under the current athletic scholarship model imposed by the NCAA and its member institutions. As noted by Mary Willingham, a former academic support services professional from the University of North Carolina, these unjust activities amount to a civil rights issue, as Black college athletes are overrepresented in men's basketball and football (Willingham, 2014). Other journalists have also levied this charge, including Taylor Branch (2011) in his essay detailing the current state of college athletics and the unfair practices imposed on Black athletes.

The aforementioned examples are only some of the myriad ethical issues plaguing intercollegiate sport today. Given this context, we put forward this special issue focusing on ethical leadership in intercollegiate sport. In doing so, we sought to recognize, and advocate for, scholarship in the field that is dedicated to enhancing ethical leadership and reducing unethical behavior within intercollegiate athletics. The papers included in this special issue critically evaluate college athletes' rights within the context of revenue producing sports (Staurowsky, 2014); closely examine the opportunities and challenges of being an ethical leader in intercollegiate sport from the perspective of an athletic director (Roby, 2014); develop a conceptual model for ethical leadership decision-making in intercollegiate sport (Sagas \& Wigley, 2014); and refocus an ethical lens on leadership of intercollegiate sport along with a call for servant leadership in administration (DeSensi, 2014).

It must be noted that these papers address only some of the challenges and opportunities necessary for ethical leadership in intercollegiate sport. In this introduction, we provide a foundation of ethical leadership, discuss the outcomes associated with ethical leaders, highlight the papers included in this special issue, and finally, identify future directions for research regarding ethical leadership. It is our hope that as a greater understanding of ethical leadership is presented to researchers and practitioners, and as they apply scholarship and practice to addressing these issues, the frequency and severity of unethical conduct within intercollegiate sport will diminish and new leaders will emerge to address these issues so as to best support college athletes.

\section{Ethical Leadership Defined}

Before discussing the role of ethical leadership in the intercollegiate athletics context, we first highlight the most recognized definition of ethical leadership: "the demonstration of normatively appropriate conduct through personal actions 
and interpersonal relationships, and the promotion of such conduct to followers through two-way communication, reinforcement, and decision-making" (Mayer, Kuenzi, Greenbaum, Bardes, \& Salvador, 2009, p. 120). This definition is grounded in social learning theory (Bandura 1986), and as such, to influence others, an ethical leader "must be viewed as an attractive, credible, and legitimate role model who engages in normatively appropriate behavior and makes the ethics message salient" (Mayer et al., 2009, p. 130). There must be explicit ethics-based communication with employees as well as reinforcement of ethically appropriate behavior demonstrated by the leader and by subordinates. Behaviors established by ethical leaders are context dependent. Given the intercollegiate athletics setting and the variety of individuals working within athletic departments (e.g., administrators, staff, coaches, interns, graduate assistants, volunteers), the influence of the athletic director displaying ethical leadership can be critical. An important tenet of ethical leadership is that the leader's ethical behavior will be reproduced by subordinates; that is, subordinates will act ethically if such behavior is demonstrated by their leader (Mayer et al., 2009).

Further, it is important to recognize organizational context when examining ethical leadership. To date, few scholars have examined subordinate (e.g., staff, coaches, athletes) perceptions of ethical leadership of athletic directors or other intercollegiate athletics officials. There has been some work related to how leadership influences development of an ethical climate in intercollegiate sport (Burton $\&$ Welty Peachey, 2013a), but the emphasis in that analysis was on evaluation of servant leadership (which has components of ethical leadership-see Parris \& Welty Peachey, 2013), not on ethical leadership, per se. Thus, the opportunity to contribute to the understanding of ethical leadership within intercollegiate athletics is robust.

\section{Constructing an Ethical Environment in Intercollegiate Athletics}

Following the tenets of social learning theory (Bandura, 1986), subordinates model the behaviors of their leaders. If leaders practice ethical decision-making and act in an ethical manner, their employees will model this behavior. In addition, ethical leaders provide rewards for ethical behavior and punish unethical behavior. These rewards or punishments further reinforce ethical behaviors by subordinates (Brown, Treviño, \& Harrison, 2005; Treviño, Brown, \& Hartman, 2003). An important caveat to role modeling of ethical leadership behavior is that subordinates will look to model the behavior of legitimate and credible leaders (Brown et al., 2005). Therefore, leaders must act in an ethical manner, and must practice what they preach, serving as proactive role models for ethical conduct (Brown \& Treviño, 2006). Further, ethical leaders must live by ethical principles and act in an ethical manner in all facets of their lives in order for subordinates to model ethical behaviors (Brown \& Treviño, 2006; Roby, 2014). This modeling of legitimate, credible ethical leadership may be considered challenging in the current climate of intercollegiate sport, with its emphasis on winning, TV revenue, and donor support (Sagas \& Wigley, 2014; Staurowsky, 2014). Leaders can gain the attention of subordinates when they focus on ethics and ethical behavior within the context of their organizations (Treviño et al., 2003). 


\section{Athletic Directors as Moral Managers}

An important aspect exhibited by an ethical leader, as described by Treviño and colleagues (2003), is moral management. Moral managers:

make ethics an explicit part of their leadership agenda by communicating an ethics and values message, by visibly and intentionally role modeling ethical behavior, and by using the reward system (rewards and discipline) to hold followers accountable for ethical conduct (Brown \& Treviño, 2006, p. 597).

Acting as a moral manager within the context of intercollegiate athletics, an athletic director must be explicit in her or his communication of an ethics and values message (Roby, 2014). More importantly, modeling ethical behavior as a moral manager can occur in interactions with athletes, support and leadership of athletics administration staff, recruitment and selection of coaches (most importantly high profile coaches in men's basketball and football), and decisions on allocation of resources. It is important to note that athletic directors must go beyond merely generating codes of ethics for their department. A code of ethics should be used to "guide, motivate, and monitor the performance of sport managers in the ethical delivery of the services of the organization" (DeSensi \& Rosenberg, 2010, p. 137). Moreover, athletic directors must enforce the code and apply it equally to all employees and athletes within the department, not just hang it on the wall and forget about it. They must also actively lead in an ethical manner, as their ethical leadership will have a more significant impact on athletic staff behavior than only establishing a code of ethics (Schaubroeck et al., 2012).

\section{Cascading Effects of Ethical Leadership}

Ethical leadership has been demonstrated to have a cascading effect on those in leadership positions below top management. Individuals in supervisory positions take cues on leadership behavior from those in position above them (Mayer et al., 2009). As Schaubroeck et al. (2012) notes, "If unethical behavior is to be addressed in organizations, authority figures must know about it and therefore must set conditions to promote follower reporting" (p. 1056). Within intercollegiate athletic organizational structures, specifically at the major college divisions (Football Bowl Subdivision schools), there are several associate or assistant athletic directors reporting directly to the athletic director. Ethical leadership flows from top-level leaders through to lower-level supervisors, and those supervisors subsequently have a positive influence, through ethical leadership, on subordinates (Mayer et al., 2009). Athletic directors operating as ethical leaders can influence their associate and assistant athletic directors to act in an ethical manner (Roby, 2014). Athletic directors operating in an ethical way can make clear that they will "not condone unethical behavior while also presenting persuasive arguments as to the benefits of ethical practices to subordinate leaders" (Schaubroeck et al., 2012, p. 1060). Employees within the athletic department will take cues from both their athletic directors and from associate/assistant athletic directors, and also operate in an ethical manner. This cascading effect of ethical leadership (Mayer et al., 2009) will be critical to fostering and maintaining an ethical climate or culture. 


\section{Establishing an Ethical Culture}

Ethical leaders can act as a "social contagion" working to shape an ethical climate or ethical culture within the organizations they lead (Neubert, Carlson, Kacmar, Roberts, \& Chonko, 2009). Ethical culture is understood to include "the interplay among the ethics-related formal (e.g., rules and policies, performance management systems) and informal (e.g., norms, language, rituals) organizational systems that influence employee ethical and unethical behavior" (Treviño, den Nieuwenboer, \& Kish-Gephart, 2014, p. 641). Athletic directors leading in an ethical manner can establish an ethical culture within their athletic departments (Roby, 2014). Athletic directors operating in a fair, honest, trustworthy manner can "create a virtuous cycle in which ethical leadership behavior perpetuates an ethical work climate that allows subordinates to flourish" (Neubert et al., 2009, p. 165). The establishment of an ethical culture can help to reduce unethical behavior or ethical transgressions, and can also serve to increase the beliefs of employees that they can also act as moral agents (Neubert et al., 2009; Schaubroeck et al., 2012).

Within intercollegiate athletic departments, there are multiple layers operating distally to the athletic director. Through enactment of ethical leadership behaviors, athletic directors support the development of an ethical culture across the entire athletic department that can also cascade to the cultures of operating units within the department (e.g., marketing, operations, compliance, teams). Further, the establishment of an ethical culture within an athletic department can support positive ethical behavior and reduce ethical transgressions by employees. Ethical leadership demonstrated by the athletic director not only plays an important role by directly influencing a shared ethical understanding among those in departments below the athletic director, but also indirectly by the formation of an ethical culture throughout the athletic department (Schaubroeck et al., 2012). An athletic director leading in an ethical manner influences employees by acting fairly and following the rules, however, he/she must also be aware that communication of information and interaction with employees will also influence the development of an ethical culture (Neubert et al., 2013).

\section{Influence of Ethical Leadership on Employees}

Social exchange theory (Blau, 1964) helps explain the influence of ethical leadership on employees, as employees might feel a sense of obligation or indebtedness to their leaders because of their fairness and trustworthiness (Brown \& Mitchell, 2010). As a result, employees led by an ethical leader demonstrate more positive behaviors at work, such as willingness to help coworkers with their work assignments and adjusting their work schedules to accommodate coworkers, and demonstrate fewer deviant behaviors, such as ignoring coworkers or instigating conflict with coworkers (Avey, Palanski, \& Walumbwa, 2011; Kacmar, Bachrach, Harris, \& Zivnuska, 2011; Mayer, Aquino, Greenbaum, \& Kuenzi, 2012). In addition, ethical leaders have significant influence on employee job satisfaction and organizational commitment (Sharif \& Scandura, 2013). Further, employees are more likely to raise concerns or address conflict within their workplace when led by an ethical leader (Walumbwa \& Schaubroeck, 2009). 
Within an intercollegiate athletics context, perhaps one of the most important employee outcomes associated with ethical leadership might be an increase in employee voice. Ethical leaders can create an environment in which subordinates feel better able to articulate concerns or address conflict in their daily activities. Ethical leadership was found to "liberate employees to engage in more open forums about work processes without fear of censorship or other adverse work outcomes" (Walumbwa \& Schaubroeck, 2009, p. 1283). The number of individuals working in an athletic department, particularly at the Division I level, necessitates decision making at multiple levels of the organization. Employees who feel more open to discuss how things are being done within their departments may be more likely to report unethical or questionable decisions that may or may not be in violation of NCAA rules, or, as Sagas and Wigley (2014) explain, do the right thing rather than do things right.

Further, relationships with employees or peers within an organization operate in conjunction with ethical leadership to influence reporting of misconduct (Mayer, Nurmohamed, Treviño, Shapiro, \& Schminke, 2013). Employee likelihood to report unethical conduct is dependent on the ethical behavior of her or his coworkers, and therefore can be enhanced or diminished based on coworker ethical behavior. Further, perceptions of retaliation mediate this influence, such that employees are less likely to report an ethical violation if they perceive coworkers will retaliate against them (Mayer et al., 2013). Unfortunately, there are many leaders in intercollegiate sport who are not leading ethically, or who are not giving voice to employees who have highlighted unethical behavior. When employees within intercollegiate athletic departments have spoken out about unethical practices, notably women working in academic support services, they have been subject to hostile treatment by colleagues, administrators, and other leaders within the NCAA (Farrey, 2003).

\section{Papers in this Special Issue}

Staurowsky (2014) examines how leaders in intercollegiate sport have responded to college athletes seeking to collectively bargain. In her commentary, Staurowsky asserts that the ethical obligation to ensure academic freedom for all students on a college campus is denied to students participating in intercollegiate athletics, most specifically in the revenue producing sports of football and men's basketball. Following a conceptual framework that situates college athletes as neither workers nor students, she argues that they are therefore disadvantaged when attempting to assert their rights. Leaders have failed when college athletes are denied the basic rights of academic freedom afforded to all students, including the right to free speech and free assembly.

Roby (2014) provides a first-hand account of how to enact and practice ethical leadership within the Division I intercollegiate athletics context. Roby has a wealth of experience leading a department that has undergone significant organizational change. He asserts that leaders in intercollegiate athletics must have values of conviction, not values of convenience. Roby describes the importance of values-driven leadership, leading in a manner that holds to one's ascribed values and recognizing the purpose for leading within the context of intercollegiate athletics.

Sagas and Wigley (2014) develop a conceptual model of ethical decisionmaking within intercollegiate athletics (College Athletics Ethical Leadership Continuum) and provide four case studies from the Division I and Division III settings to support the need for this model. Arguing that decisions made by leaders in intercollegiate athletics more often support doing things right and not doing the 
right things, they demonstrate how the well-being of college athletes is compromised when failing to follow an ethical decision-making framework. The model put forward in their paper includes two fundamental principles: holding the college athlete as the primary stakeholder of college sport activities and critically analyzing present decision making to provide ethical leadership in the future.

Finally, DeSensi (2014) provides an examination of the ethos of sport, with a focus on developing a values approach to leading intercollegiate sport. Servant leadership is highlighted as a path toward leadership that makes informed decisions based on ethical and moral consideration. DeSensi notes that character education must be considered in the ethos of intercollegiate sport in its current form. As such, leaders in intercollegiate sport must make it a priority to educate athletes, coaches, and athletic administrators to consider the "ethical perspectives regarding the ethos, character building and moral development of intercollegiate sport" (p. 61). Servant leadership is highlighted as the leadership approach most needed to meet the need for ethical development (through ethos, character, values) in intercollegiate sport.

\section{Future Research Directions}

In response to the call for papers for this special issue, the majority of work submitted for consideration was conceptual or commentary rather than empirical. In fact, this special issue contains only conceptual papers and commentaries. The contents of this special issue highlight that sport management scholars have the opportunity to address a gap in the literature and to conduct empirical studies investigating ethical leadership in the intercollegiate sport context. We believe the conceptual work and commentaries included here, and in other publications (see Burton \& Welty Peachey, 2013b), have laid the foundation for much-needed empirical scholarship. Below, we highlight several intriguing directions related to research in ethical leadership and intercollegiate sport that scholars may wish to consider. We do not mean to suggest that these are the only avenues for future research, but merely to put forth these suggestions to stimulate the creative energies of the sport management academy.

First, a worthwhile line of inquiry would be to examine perceptions of ethical leadership. To our knowledge, there has been no research that has examined subordinate perceptions of ethical leadership of athletic directors or other intercollegiate athletics leaders. Scholars could investigate and compare these perceptions across the three Divisions to ascertain similarities and differences. In addition, it would be fruitful to examine the relationship between ethical leadership and organizational performance (e.g., winning, financial performance, donations received) within each Division. Does ethical leadership lead to better organizational performance across Divisions, or only within some Divisions? While the relationship between ethical leadership and organizational performance would be important to examine, the concept of being a moral manager within an intercollegiate context has also yet to be examined, and as such, evaluating whether athletic directors leading as moral managers result in positive ethical outcomes (e.g., fewer NCAA infractions or deviant behavior, higher athlete retention and graduation rates) would contribute to the understanding of ethical leadership in college athletics. In addition, other outcome variables may also be related to ethical leadership and should be investigated within the intercollegiate sport context, such as job satisfaction, satisfaction with the leader, employee effort, and organizational commitment, among others. 
In a related vein, scholars could examine how ethical leadership of the athletic director or other senior leaders in athletic departments leads to the emergence of employee voice (Walumbwa \& Schaubroeck, 2009), and how employee voice may then be associated with increased ethical behavior of staff and positive ethical outcomes within the department. We have not been able to identify research within an intercollegiate context that has examined the concept of voice. However, we have noted a level of distrust and fear on behalf of subordinates in athletic departments in regard to giving voice to concerns associated with the leadership of athletic directors. As an example, one of our doctoral students noted an approximately $50 \%$ decrease in willingness of subordinates to participate in an online survey evaluating an athletic director's ethical leadership behavior despite assurances that the survey was completely confidential and no data would be shared with their respective athletic directors. Perceptions of retaliation by athletic directors may be a factor contributing to the reluctance to answer a survey regarding ethical leadership, and this perception could also contribute to a decline in reporting unethical behavior (Mayer et al., 2013).

Future research could also investigate the barriers and challenges that leaders in intercollegiate athletics face with regards to ethical leadership. What barriers and challenges prevent or inhibit leaders from acting consistently in an ethical manner? Do these barriers and challenges differ across Divisions? What strategies do ethical leaders use to overcome these barriers? Finally, it would be worthwhile to examine how leadership styles, such as servant (Greenleaf, 1977; van Dierendonck, 2011) and authentic (Avolio \& Gardner, 2005), exhibit aspects of ethical leadership in the intercollegiate context. Do subordinates perceive servant and authentic leaders to be more ethical, and do these leadership styles subsequently lead to better organizational and ethical outcomes, more so than other contemporary styles of leadership such as transformational and transactional (Bass, 1985)?

To conclude, with the prevelance of unethical conduct and scandals in intercollegiate sport today, we believe this special issue is both timely and highly relevant to the conduct and administration of intercollegiate athletics. It is our hope that the papers contained herein will encourage and stimulate scholars and practitioners alike to focus concerted thought and energies on improving ethical leadership in the collegiate sport environment. By doing such, we can help address the ethical imbalance in intercollegiate sport and lead with morals, integrity, and conviction.

\section{Note}

1. See Staurowsky (2014) for a discussion of the term student-athlete. We use the term college athlete throughout this paper.

\section{References}

Avey, J.B., Palanski, M.E., \& Walumbwa, F.O. (2011). When leadership goes unnoticed: The moderating role of follower self-esteem on the relationship between ethical leadership and follower behavior. Journal of Business Ethics, 98(4), 573-582. doi:10.1007/ s10551-010-0610-2

Avolio, B.J., \& Gardner, W.L. (2005). Authentic leadership development: Getting to the root of positive forms of leadership. The Leadership Quarterly, 16, 315-338. doi:10.1016/j. leaqua.2005.03.001 
Bandura, A. (1986). Social foundations of thought and action: A social cognitive theory. Englewood Cliffs, NJ: Prentice Hall.

Barrett, P.M. (2014, April 22). UNC-Fake classes whistleblower resigns after meeting with chancellor. Retrieved from http://www.businessweek.com/articles/2014-04-22/marywillingham-the-fake-classes-whistleblower-at-university-of-north-carolina-resignsafter-meeting-with-chancellor

Bass, B.M. (1985). Leadership and performance beyond expectations. New York: Free Press. Blau, P.M. (1964). Exchange and power in social life. NJ: Transaction Publishers.

Branch, T. (2011, September 7). The shame of college sports. Retrieved from http://www. theatlantic.com/magazine/archive/2011/10/the-shame-of-college-sports/308643/

Brown, M.E., \& Mitchell, M.S. (2010). Ethical and unethical leadership. Business Ethics Quarterly, 20(4), 583-616. doi:10.5840/beq201020439

Brown, M.E., \& Treviño, L.K. (2006). Ethical leadership: A review and future directions. The Leadership Quarterly, 17(6), 595-616. doi:10.1016/j.leaqua.2006.10.004

Brown, M.E., Treviño, L.K., \& Harrison, D.A. (2005). Ethical leadership: A social learning perspective for construct development and testing. Organizational Behavior and Human Decision Processes, 97, 117-134. doi:10.1016/j.obhdp.2005.03.002

Burton, L.J., \& Welty Peachey, J. (2013a, June). The role of servant leadership in developing an ethical climate in intercollegiate athletics. Paper presented at the meeting of the North American Society for Sport Management.

Burton, L.J., \& Welty Peachey, J. (2013b). The call for servant leadership in intercollegiate athletics. Quest, 65, 354-371. doi:10.1080/00336297.2013.791870

Cunningham, G.B. (2012). Diversity and academic reform. Journal of Intercollegiate Sport, $5,54-59$.

DeSensi, J. T. (2014). Sport: An ethos based on values and servant leadership. Journal of Intercollegiate Sport, 7, 58-63.

DeSensi, J.T., \& Rosenberg, D. (2010). Ethics and morality in sport management. Morgantown, WV: Fitness Information Technology.

ESPN. (2011, December 15). NCAA, ESPN agree to a new deal. Retrieved from http://espn. go.com/college-sports/story/_id/7357065/ncaa-espn-agree-tv-deal-2023-24

Farrey, T. (2003, October 7). Defining bravery in college sports. Retrieved from http://sports. espn.go.com/nba/columns/story?columnist=hollinger_john\&id=1632030\&campaign= rsssrch\&source $=$ NBAHeadlines

Fenno, N. (2014, April 25). New lawsuit targets NCAA, 11 conferences over scholarships. Retrieved from http://www.latimes.com/sports/sportsnow/la-sp-sn-lawsuit-targets-ncaascholarships-20140425,0,7404263.story\#axzz30CA644Yc

Grasgreen, A. (2014, March 28). Racial divide on athletes' rights. Retrieved from http:// www.insidehighered.com/news/2014/03/28/racial-divide-public-opinion-payingathletes\#sthash.mDYYBiUS.dpbs

Greenleaf, R.K. (1977). Servant-leadership: A journey into the nature of legitimate power and greatness. New York: Paulist Press.

Jacobson, G. (2014, April 3). Inside the Final Four finances: The march toward \$1 billion in revenue. Retrieved from http://www.dallasnews.com/sports/college-sports/ncaatournament/the-scene/20140403-inside-the-final-four-finances-the-march-toward1-billion-in-revenue.ece

Kacmar, K.M., Bachrach, D.G., Harris, K.J., \& Zivnuska, S. (2011). Fostering good citizenship through ethical leadership: Exploring the moderating role of gender and organizational politics. The Journal of Applied Psychology, 96(3), 633-642. PubMed doi:10.1037/a0021872

Lederman, D. (2014, April 16). College sports' antitrust vulnerability. Retrieved from http:// www.insidehighered.com/news/2014/04/16/sports-antitrust-lawyers-latest-target-ncaascholarship-limits\#sthash.AmO6G4Kr.dpbs 
Mayer, D.M., Aquino, K., Greenbaum, R.L., \& Kuenzi, M. (2012). Who displays ethical leadership, and why does it matter? An examination of antecedents and consequences of ethical leadership. Academy of Management Journal, 55(1), 151-171. doi:10.5465/ amj.2008.0276

Mayer, D. M., Kuenzi, M., Greenbaum, R., Bardes, M., \& Salvador, R. (Bombie). (2009). How low does ethical leadership flow? Test of a trickle-down model. Organizational Behavior and Human Decision Processes, 108(1), 1-13. doi:10.1016/j.obhdp.2008.04.002

Mayer, D.M., Nurmohamed, S., Treviño, L.K., Shapiro, D.L., \& Schminke, M. (2013). Encouraging employees to report unethical conduct internally: It takes a village. Organizational Behavior and Human Decision Processes, 121(1), 89-103. doi:10.1016/j. obhdp.2013.01.002

Neubert, M.J., Carlson, D.S., Kacmar, K.M., Roberts, J.A., \& Chonko, L.B. (2009). The virtuous influence of ethical leadership behavior: Evidence from the field. Journal of Business Ethics, 90(2), 157-170. doi:10.1007/s10551-009-0037-9

O'Toole, T. (2010, April 22). NCAA reaches 14-year deal with CBS/Turner for men's basketball tournament, which expands to 68 teams for now. Retrieved from http://content. usatoday.com/communities/campusrivalry/post/2010/04/ncaa-reaches-14-year-dealwith-cbsturner/1\#.U2pWSi-aFz8

Parris, D., \& Welty Peachey, J. (2013). Theory to practice: A systematic literature review of servant leadership applied studies. Journal of Business Ethics, 113, 377-393. doi:10.1007/s10551-012-1322-6

Roby, P. (2014). Ethical leadership in college athletics. Journal of Intercollegiate Sport, 7, 35-39.

Sagas, M., \& Wigley, B.J. (2014). Gray area ethical leadership in the NCAA: The ethics of doing the wrong things right. Journal of Intercollegiate Sport, 7, 40-57.

Schaubroeck, J.M., Hannah, S.T., Avolio, B.J., Kozlowski, S.W., Lord, R.G., Treviño, L.K., . . . Peng, A.C. (2012). Embedding ethical leadership within and across organization levels. Academy of Management Journal, 55(5), 1053-1078. doi:10.5465/amj.2011.0064

Sharif, M.M., \& Scandura, T.A. (2013). Do perceptions of ethical conduct matter during organizational change? Ethical leadership and employee involvement. Journal of Business Ethics, 2, 1-12.

Southall, R.M., Eckard, W., Nagel, M.S., Keith, E., \& Blake, C. (2013). 2013 Adjusted graduation gap report: NCAA Division I football. College Sport Research Institute. Retrieved from http://csri-sc.org/wp-content/uploads/2013/09/CSRI_2013_AGG_ NCAA_D-I_FB.pdf

Staurowsky, E. J. (2014). College athletes' rights in the age of the super conference: The case of the All Players United campaign. Journal of Intercollegiate Sport, 7, 11-34.

Treviño, L.K., Brown, M., \& Hartman, L.P. (2003). A qualitative investigation of perceived executive ethical leadership: Perceptions from inside and outside the executive suite. Human Relations, 56(1), 5-37. doi:10.1177/0018726703056001448

Treviño, L.K., den Nieuwenboer, N.A., \& Kish-Gephart, J.J. (2014). (Un) Ethical behavior in organizations. Annual Review of Psychology, 65, 635-660. PubMed doi:10.1146/ annurev-psych-113011-143745

van Dierendonck, D. (2011). Servant leadership: A review and synthesis. Journal of Management, 37, 1228-1261. doi:10.1177/0149206310380462

Walumbwa, F.O., \& Schaubroeck, J. (2009). Leader personality traits and employee voice behavior: Mediating roles of ethical leadership and work group psychological safety. The Journal of Applied Psychology, 94(5), 1275-1286. PubMed doi:10.1037/a0015848

Willingham, M. (2014, April 24). Schooled: The price of college sport. Symposium conducted at 2014 Conference on College Sport hosted by the College Sport Research Institute, Columbia, SC. 